\title{
Cartas de crédito como medio de pago que genera confianza en el mundo de los negocios internacionales
}

\section{Letters of credit as a means of payment that generates confidence in the world of international business}

Econ. Lucía Magdalena Pico Versoza, MBA

Universidad Internacional del Ecuador, Ecuador

Ing. Ricardo Rafael Coello Yagual

Universidad Internacional del Ecuador, Ecuador

Autor por correspondencia: lupicove@internacional.edu.ec, ricoelloya @internacional.edu.ec Fecha de recepción: 21 de Febrero de 2018 - Fecha de aceptación: 15 de agosto de 2018

\section{Resumen}

La presente investigación responde a un estudio de tipo descriptivo, cuyo objetivo es conocer la seguridad y confianza que proporcionan las cartas de crédito en las transacciones comerciales. Para lograr el objetivo antes mencionado se comienza con la premisa desde conocer ¿Qué es una carta de crédito?, y los beneficios que pueden obtener las partes involucradas. Ecuador posee entidades financieras encargadas de asesorar y emitir cartas de crédito a las empresas que realizan comercio internacional y que así lo requieran como medio de confiabilidad que garantice operaciones comerciales, sin embargo este a su vez presenta características y normas que regulan y controlan su uso dentro de parámetros internacionales. Se concluye el presente estudio con la descripción de los beneficios que obtienen las partes involucradas a pesar de los costos que inciden en el uso de este documento.

Palabras Claves: cartas de crédito; UCP 600; comercio internacional; irrevocable

\begin{abstract}
The present investigation responds to a descriptive study, whose objective is to know the security and confidence that letters of credit provide in commercial transactions. To achieve the aforementioned objective begins with the premise from knowing what is a letter of credit? And the benefits that can be obtained by the parties involved. Ecuador has financial entities in charge of advising and issuing letters of credit to companies that carry out international trade and that require it as a means of reliability to guarantee commercial operations, however this in turn has characteristics and rules that regulate and control their use within of international parameters. The present study concludes with the description of the benefits obtained by the parties involved despite the costs that affect the use of this document.
\end{abstract}

Key words: letter of credit; UCP 600; international commerce; irrevocable 


\section{Introducción}

La carta de crédito es un documento comercial en muchas ocasiones utilizada como medio para asegurar el cumplimiento del pago de bienes y servicios dentro de una operación de comercio internacional, ya que al poseer reglas y procesos que se deben cumplir en un tiempo determinado por las partes que intervienen, se minimizan los riesgos en las transacciones comerciales internacionales.

Sin embargo, para realizar exportaciones o importaciones, es de suma importancia que la persona encargada de la gestión, tenga el conocimiento adecuado de diversos términos y leyes de negociación internacional como el tipo de cambio, las divisas y métodos para negociar en el trascurso del envió o entrega de la mercadería, destacándose los incoterms y las formas de pago en una transacción de comercio internacional.

Existen varios métodos por los cuales se puede realizar una compra o venta de manera internacional, en el presente trabajo de investigación, se definirá a las cartas de crédito como instrumentos confiables o seguros para realizar transacciones comerciales en el mercado internacional. También se mencionará la función y el beneficio que le genera a una empresa el uso de las cartas de crédito.

Revisión de literatura

Para iniciar esta investigación, es necesario responder a la siguiente pregunta: ¿Qué es una carta de crédito?, de acuerdo a (Mejía, 2004) una carta de crédito es:

"un instrumento de pago, sujeto a regulaciones internacionales, mediante el cual un banco emisor, obrando por solicitud y conformidad con las instrucciones de un cliente (ordenante), debe hacer un pago a un tercero (beneficiario), contra la entrega de los documentos exigidos, siempre y cuando se cumplan los términos y condiciones de crédito"

Las cartas de crédito aseguran los bienes participantes en las transacciones comerciales internacionales, beneficiando tanto al importador como al exportador, ya que el importador según las cláusulas establecidas en la carta de crédito se asegura de tener la mercadería en el tiempo y forma negociado con el exportador evitando pagar por adelantado y en cuanto al exportador el beneficio obtenido al acogerse a la carta de crédito es el obtener su pago por la mercadería entregada, evitando posibles estafas.

Es así, que uno de los motivos que lleva a que tanto exportadores como importadores adopten el mecanismo de uso de cartas de crédito como instrumento de pago es la minimización del riesgo en el cobro, al estar reguladas y respaldadas por leyes y organismos internacionales, encargados de mediar ante cualquier situación que complique y perjudique a las partes que intervienen en la transacción internacional.

Se instrumentan de acuerdo con las Reglas y Usos Uniformes Relativos a los Créditos Documentarios - UCP 600 de la Cámara de Comercio Internacional - ICC, conocidas también 
como "brochure 600". (BCE , 2009). Las UCP 600 permiten que no surjan interpretaciones incorrectas en cuanto a condiciones y usos de las cartas de crédito, debido que son un lenguaje único conocido y utilizado a menudo por las entidades financieras y empresas dedicadas al comercio internacional. En caso de que las empresas novatas en el ámbito de las negociaciones internacionales sufran o se vean envueltas en conflictos comerciales, deben acogerse a las UCP 600 con el fin de resolver el percance de la manera correcta. Para la Corporación Financiera Nacional, la carta de crédito es un instrumento financiero con el cual, se emite por cuenta de su cliente un crédito documentario a favor de un exportador en el extranjero, el mismo que será pagado cuando se cumplan las condiciones establecidas entre comprador y vendedor (CFN, 2017)

De acuerdo al autor (Masqui, 2015), las cartas de crédito son necesarias en el ámbito internacional, de tal manera que nos facilitan un método de pago sea por importación o exportación de mercaderías, nos ayudan a disminuir el riesgo de que no exista el pago o el cobro de la contraparte. Así mismo (Zambrano, 2017), hace referencia a que Pro Ecuador destacó que para evitar casos de estafa la empresa exportadora debe validar la procedencia del importador o empresa con la que va a realizar negocios. En estos procesos sus oficinas comerciales buscan ayudar con las validaciones junto con los organismos de control y empresas del país de destino de la exportación. Adicional a esto, se deben aplicar instrumentos financieros como cartas de crédito y/o cobranzas a manera de garantía.

Entre los beneficios que generan las cartas de crédito se encuentran:

- Seguridad en el pago, es decir la función del banco como intermediario garantiza que el pago se realice para el proveedor y la entrega de la mercancía para el comprador.

- Garantía en el cumplimiento de condiciones de negociación, debido a que cualquier condición que requiera el comprador o proveedor y que esté debidamente expresada en la carta de crédito con pleno consentimiento de las partes, debe cumplirse, situación que será supervisada por el banco.

- Disminución de riesgo documental, ya que cada banco cuenta con agentes especializados en comercio exterior, quienes serán los encargados de revisar minuciosamente que los documentos habilitantes se encuentren de forma correcta, siendo este un punto que resalta su importancia debido a que se debe ajustar a las condiciones de cada aduana tanto en el país exportador como en el país importador.

- Acceso a importaciones a plazo, es decir generalmente los bancos analizan la situación crediticia del ordenante, y en base a esto podrán ofrecer pago a la vista o financiado mediante crédito a plazo diferido, con los respectivos intereses bancarios.

Este servicio es prestado a los importadores y exportadores de productos ecuatorianos. Por ejemplo, en Ecuador las empresas pueden acceder a Cartas de Crédito de Exportación e Importación, Cartas de Crédito Stand By y Garantías Bancaria, siendo el monto mínimo de operación de \$50.000, la vigencia depende de las condiciones de negociación y la comisión será cobrada por evento. (El Telegráfo, 2017) 
De acuerdo al Banco Pichincha, entidad financiera posicionada como una de las más confiables a nivel nacional, indica los siguientes beneficios que ofrece una carta de crédito: (Banco Pichincha, 2017)

- Mejora la relación comercial con los proveedores ya que la representación del Banco Pichincha respalda la solidez financiera del importador.

- Elimina riesgos innecesarios con respecto al manejo de sus documentos comerciales y financieros, además de los inherentes al pago de la importación en el exterior.

- Optimiza los recursos financieros del importador, ya que no afecta directamente su liquidez hasta el vencimiento de la carta de crédito (en el caso de que esta se pague a plazos).

- Asegura al importador que los documentos serán revisados apropiadamente por expertos en el tema.

- Posibilita el control de las fechas de entrega de la mercadería o servicios.

- Incrementa la posibilidad de solicitar financiamiento directamente al proveedor.

Este instrumento, básicamente sirve para eliminar el riesgo que conlleva un comprador, cuando no sea capaz de pagar de manera completa o parcial al vendedor, entonces el banco termina con el pago restante. (El Mundo Infinito, 2017)

Anteriormente en las negociaciones internacionales, se presentaban dudas en el momento de pagar y las mismas se prestaban para fraudes, debido a que confiaba de manera única y exclusivamente en la buena fe de las partes involucradas, sin embargo, con la participación de los bancos en escena, las relaciones comerciales han ganado en seguridad, volumen y confianza.

En la actualidad, las cartas de crédito han ganado la confiabilidad necesaria, y llego a convertirse en el principal instrumento de pago en el comercio internacional, gracias a su relativa simplicidad y a la seguridad que ofrece para las partes involucradas en la negociación. (Verde, 2016). En el Ecuador, las cartas de crédito tienen el apoyo de las distintas instituciones financieras y gubernamentales, su uso ha ayudado a abarcar otros mercados fuera del territorio local, facilitando las transacciones comerciales con otros países.

Otro punto a destacar de las cartas de crédito, es que ha facilitado las relaciones comerciales, a pesar de la distancia que se pueda presentar entre un comprador y un vendedor, de manera segura y confiable, ya que el tema de pagar la mercadería es un asunto relevante para las compañías involucradas.

Como conocimiento general, se detallarán a continuación los distintos tipos de carta de crédito que existen para negociar un acuerdo: 
Tabla 1. Tipos de carta de crédito

\begin{tabular}{|c|c|}
\hline Tipo & Descripción \\
\hline Directa & $\begin{array}{l}\text { Los pagos solo se pueden realizar a los beneficiarios nombrados en el } \\
\text { documento y no pueden intervenir terceros }\end{array}$ \\
\hline Irrevocable & $\begin{array}{l}\text { No pueden ser revocadas sin el consentimiento de los vendedores por ninguna } \\
\text { parte }\end{array}$ \\
\hline Revocable & $\begin{array}{l}\text { Puede ser revocable sin previo aviso por el banco a pedido del cliente y aunque } \\
\text { el vendedor tenga alguna objeción }\end{array}$ \\
\hline Confirmada & $\begin{array}{l}\text { Esta es una segunda garantía que compromete a las partes al pago y } \\
\text { normalmente se realiza cuando la institución que expide las cartas no es muy } \\
\text { confiable. }\end{array}$ \\
\hline Sin confirmar & $\begin{array}{l}\text { Solo requiere de un banco, por lo que un segundo no otorga más garantías y } \\
\text { toda la responsabilidad recae sobre el primero }\end{array}$ \\
\hline Transferible & $\begin{array}{l}\text { Permite al beneficiario asignar a alguien más todo el crédito disponible por lo } \\
\text { que se crea un segundo beneficiario y el banco se refiere entonces a la persona } \\
\text { interesada como primer beneficiario }\end{array}$ \\
\hline Standby & $\begin{array}{l}\text { Es una opción más flexible tanto para cliente como para quien vende ya que se } \\
\text { asegura que el pago se realice a pesar de que suceda alguna clase de imprevisto }\end{array}$ \\
\hline Back to Back & Se involucran dos cartas donde la primera establece expedir una segunda \\
\hline Rotativa & $\begin{array}{l}\text { Se utilizan cuando se tiene planeado realizar varios pagos o negocios } \\
\text { continuamente pero tomando en cuenta que al establecerse las condiciones también } \\
\text { se hacen los plazos de tiempo que tienen que considerar las personas involucradas }\end{array}$ \\
\hline Clausula roja & $\begin{array}{l}\text { Suelen mostrarse con este color en el documento para dejar claro que se solicita } \\
\text { un adelanto en el compromiso }\end{array}$ \\
\hline A la vista & $\begin{array}{l}\text { Los pagos se realizan justo después de haber presentado la documentación } \\
\text { pertinente y normalmente en un plazo no mayor a una semana }\end{array}$ \\
\hline Diferido & $\begin{array}{l}\text { A pesar de presentar los documentos que acreditan el pago, éste no se realiza } \\
\text { inmediatamente y se tiene que esperar un periodo de tiempo establecido desde el } \\
\text { principio en el papel }\end{array}$ \\
\hline $\begin{array}{l}\text { Importación y } \\
\text { Exportación }\end{array}$ & Son utilizadas para el cumplimiento de tratos internacionales \\
\hline
\end{tabular}

Nota. El Mundo Infinito. (2017). El Mundo Infinito. Obtenido de https://elmundoinfinito.com/tiposcarta-credito/

La mayoría de las cartas de crédito que ofrecen los bancos tanto a nivel local e internacional son irrevocables, lo que significa que no pueden ser modificadas sin consentimiento y acuerdo de las partes que intervienen, de esta manera se asegura la confiabilidad de este documento. Así también, se reconoce que todas las cartas de crédito deben ser confirmadas con el fin de garantizar la solvencia del comprador o banco emisor. Una vez que la carta de crédito está confirmada por un banco, el riesgo del país, económico y político, tanto como la capacidad del comprador para pagar, se eliminan; el banco está obligado a pagar aún si el cliente se declara en bancarrota siempre que los documentos obedezcan los términos de la carta de crédito (Rusia Export, 2008) 
Adicional se añade de manera más específica los beneficios para los exportadores, es decir para la entidad que vende en una operación de comercio internacional, el uso de las cartas de crédito:

- Asegura el pago de un banco internacional una vez que los términos de la carta de crédito se han cumplido.

- El vendedor puede decidir cuando el pago es satisfactorio y enviar la mercancía según se acuerda.

- El banco asume la responsabilidad de supervisar.

- El vendedor no necesita abrir una cuenta y otorgar condiciones de pago al comprador.

- Se reduce prácticamente el riesgo generado por retrasos de pagos.

- Proporciona a los vendedores fácil acceso a financiamiento una vez que la carta de crédito ha sido emitida a su favor.

Las cartas de crédito presentan también los siguientes beneficios para los compradores:

- Facilita financiamiento, por ejemplo, creando aceptaciones de banqueros.

- El comprador puede confirmar que la mercancía se envíe durante o antes de la fecha requerida.

- Es más seguro tratar con bancos que pagar por adelantado.

- Se pueden conseguir mejores términos y precios.

- Ningún efectivo pagado por adelantado se queda inmovilizado durante el proceso.

- Los compradores no tienen que pagar por adelantado a un país extranjero antes de recibir los documentos de propiedad de la mercancía pagada.

- Protege al comprador, debido a que el banco sólo paga al proveedor que cumple con los términos y condiciones específicas además de los documentos requeridos por el comprador.

- El comprador puede implementar una salvedad en la carta de crédito tal como una inspección de la mercancía, control de calidad, establecimiento de la producción y el horario de entrega.

\section{Conclusiones}


Las cartas de crédito son una fuente de seguridad y confianza para las partes involucradas; a pesar de que el uso de estos documentos influye en el incremento de los costos y gastos directos en cuanto al bien importado, existe un nivel de confianza mayor que permite que las negociaciones y transacciones comerciales internacionales fluyan de manera frecuente, beneficiando a las economías de los países que intervienen, adaptándose a la globalización.

En el Ecuador, las entidades financieras cuentan con el servicio de emisión y otorgamiento de las cartas de crédito a las empresas que quieren acogerse a este documento, lo que permite que las empresas de comercio internacional se acogen al uso de las cartas de crédito como instrumento que permite que sus negociaciones internacionales minimicen el riesgo al que se enfrentan al realizar estas operaciones.

Por tanto, se debe acotar que aun cuando este instrumento financiero genera costos e intereses que encarecerían la importación o exportación, genera a su vez confiabilidad y la oportunidad de un crédito a plazo para el mismo financiamiento de la operación comercial.

\section{Bibliografía}

Banco Pichincha. (2017). Banco Pichincha. Obtenido de https://www.pichincha.com/portal/Empresas/Empresas/Pichincha-COMEX/Cartas-deCredito/Importacion

BCE . (2009). Banco Central del Ecuador. Obtenido de https://contenido.bce.fin.ec/contenido.php?CNT=ARB0000996

CFN. (Septiembre de 2017). CFN. Obtenido de https://www.cfn.fin.ec/cartas-de-creditoimportacion/

El Mundo Infinito. (2017). El Mundo Infinito. Obtenido de https://elmundoinfinito.com/tiposcarta-credito/

El Telegráfo. (Septiembre de 2017). Obtenido de 20: http://www.eltelegrafo.com.ec/noticias/economia/8/la-cfn-dispone-de-usd-700-millonespara-creditos

Mejía, J. (8 de Febrero de 2004). Gestiopolis. Obtenido de https://www.gestiopolis.com/cartas-decredito-e-instrumentos-del-mercado-financiero-internacional/

Rusia Export. (21 de Marzo de 2008). WordPress. Obtenido de https://rusiaexport.wordpress.com/2008/03/21/beneficios-de-la-carta-de-credito/

Verde, P. (13 de Abril de 2016). Comercio Global. Obtenido de http://comercioglobalsinbarreras.blogspot.com/2016/04/negocio-seguro-y-confiablecarta-de.html

Masqui, E. (2015).www.todocomercioexterior.com.ec. 
Zambrano. (2017). www.expreso.ec/actualidad/estafa-exportaciones-ecuador-empresasrelacionescomerciales-AL1683705. 